\title{
FORCED CREATURES
}

\section{Zooësis in Star Wars Rebels and The Last Jedi}

\section{Spencer D. C. Keralis}

Keywords:

Star Wars Rebels, Porgs, Critical Animal Studies

Non-sentient animals have appeared in the Star Wars universe in roles both integral and decorative since $A$ New Hope premiered in 1977. From beasts of burden like the dewbacks and banthas of Tatooine and the Gungans' kaadu, to monsters like the wampa, rathtar, and dianoga; to the myriad of critters large and small that inhabit interstellar environments, animals are as much a part of the fabric of the Star Wars tapestry as the various non-human sentient species. In some cases, these creatures are mainly exotic window dressing, but in other instances, these animals are used instrumentally to advance larger narratives.

To frame my examination of the use of animals in Star Wars, I borrow performance studies scholar Una Chaudhuri's useful neologism "zooësis." Coined by Chaudhuri to articulate "the way culture makes art and meaning with the figure and body of the animal," encompasses the feelings that animals inspire, and so the affect of animals is an important part of understanding the place of the animal in the Star Wars universe (1). Ezra Bridger's interaction with animals to explore the Force and to aid the Rebellion in Star Wars Rebels offers one example of how animals are instrumentalized, and Ezra's affective response to "the figure and body" of these creatures affection, awe, revulsion, or horror - are fairly straightforward. But the lowly porg from The Last Jedi inspires different feelings: the complex affect of cuteness, combined with the desire to consume and devour the bodies of these animals. In what follows I invite my reader to consider the use of animals in Star Wars, and to question how agency is granted and denied to non-human animals in these narratives.

In Star Wars Rebels, Ezra Bridger is a Force-sensitive teenager. Represented as mixed-race, Ezra enters the story a homeless youth, surviving through grift and charm on the streets of Lothal, an Imperial-occupied city. Rebels begins 14 years after the fall of the Jedi temple, and five years before $A$ New Hope. Ezra is taken in by a cell of resistance fighters in the nascent Rebellion. Among them is Kanan Jarrus, a Jedi who managed to escape Clone Protocol 66. Jarus recognizes Ezra's bond to the Force and begins training the boy ("Spark of Rebellion"). 
A unique aspect of his training involves the exercise of the Force on non-human animals. Initially, this is merely to connect with and pacify the animal through the Force. They begin with the local fauna on Lothal - a Loth-cat. Ezra is frustrated in this exercise, at least in part because he's not comfortable exerting control over a free creature. Likewise the Loth-cat is loath to put up with being controlled, and resists admirably and effectively, tipping the scales on the reluctant Ezra ("Empire Day").

Ezra's training soon advances to larger, more dangerous creatures, including the fyrnocks, photophobic bat-bear hybrids that occupy an abandoned supply depot on asteroid base PM-1203. Surprised by the Grand Inquisitor tasked with hunting Jedi remnants, Ezra compels the fyrnocks to attack the Inquisitor and his stormtroopers. Though the troopers are easily bested, the Inquisitor is not. In a desperate act of self-preservation, Ezra draws on his fear to summon a fyrnock matriarch (Figure 1), which gives Ezra and Kanan an opportunity to escape ("Gathering Forces”).

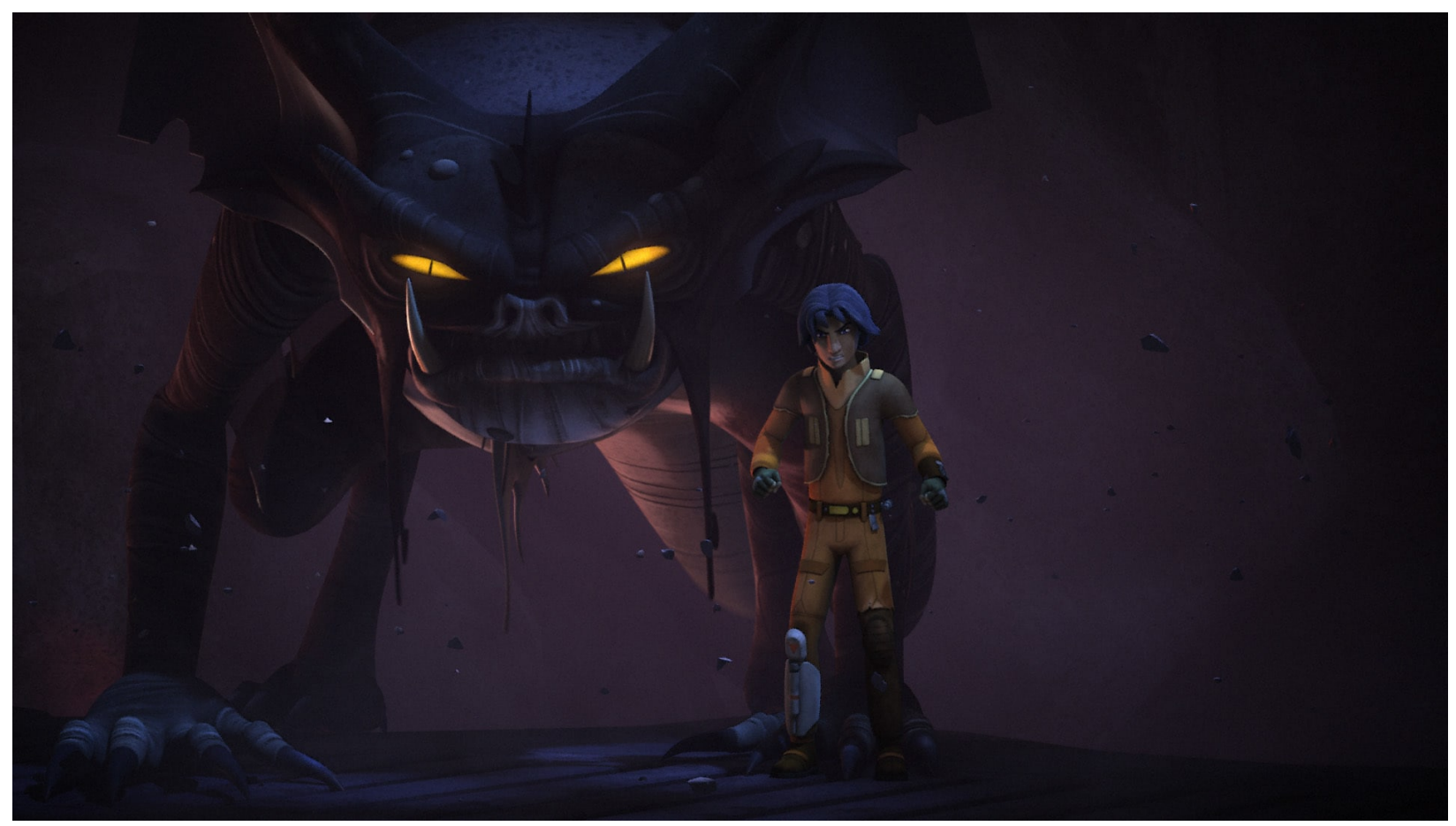

Figure 1: Ezra Bridger with the fyrnock matriarch in Star Wars Rebels.

Via: starwars.com

But this comes at a cost. Drawing on fear is, as we're well-schooled by this point, a gateway to the Dark Side. And fear remains an obstacle for Ezra, later preventing him, much to his frustration, from connecting with the spider-like krykna. In Ezra's encounter with the fyrnock matriarch, we see that the use of animals for violence, motivated by fear and powered by the Force, opens up a path to the Dark Side for the young Jedi. This shapes his journey, ultimately leading to him becoming as close to a hybrid of Sith and Jedi as we've seen in the mythos. Ezra does not, however, represent the promise of balance others here have suggested may come to pass with the convergence of Rey and Kylo Ren. He is instead pulled between two masters - Kanan Jarus and Maul. 
While I would argue that Ezra never quite finds balance in his interactions with the Force, striking a balance in relation to non-human animals is crucial to his path. He finds this, not through his connection with the Force, but through his profound connection to his home planet, Lothal. In his final confrontation with the Empire, Ezra is assisted by Loth-cats and powerful, mythic Loth-wolves. These creatures fight, not to aid the Jedi and the emerging Rebellion, but to preserve their lived environment, which is suffering an ecological catastrophe from Imperial industrialization. These creatures do not submit to Ezra, but fight alongside him for their own reasons, and exercising their own agency. Rather than fear, the Loth-wolves inspire awe in Ezra and turn the tide of the uprising on Lothal in favor of the Rebels. The vacuum-breathing purgill come to Ezra's aid in the battle above the planet. Ezra does not compel their cooperation. Rather they respond to his summons because he had previously shown them empathy and as a result discovered one of their secrets - that they are naturally able to open gateways into hyperspace. This innate talent become part of Ezra's tactics in the decisive confrontation with Grand Admiral Thrawn, propelling Ezra away from the planet along with the remnants of the Imperial fleet ("A Fool's Hope," "Family Reunion - and Farewell").

Through his interactions with the Loth-wolves and the purgill, Ezra finds a balance that allows him to interact with animals in a way that does not compel their cooperation, but rather allows them agency. He finds a way to treat animals with reciprocity rather than using the Force to treat them instrumentally. Ezra must abandon his efforts to use the Force to dominate non-human animals, in favor of interactions that allow for some reciprocity of feeling, and that allow for animals to act from their own motives, however inscrutable those may be. Respect replaces fear, allowing humans and animals to occupy parallel but separate spaces in their shared environments. Zooësis in Rebels ultimately turns on eschewing the instrumentalization of nonhuman animals so prevalent elsewhere in the Star Wars universe.

In contrast, the creation of the porgs was itself an instrumental choice. The island of Skellig Michael off the coast of Ireland, which stood in for Ahch-To, is a nesting ground for Atlantic puffins. The island's lack of native mammals make it an ideal nesting place and puffins and other seabirds are ubiquitous on the island for a significant part of the year and were impossible to avoid. Skellig Michael is part of a World Heritage Site, is a Statutory Nature Reserve, and a Special Protection Area, so the puffins and other seabirds are protected as well. How then to effectively use this dramatic location without delaying shooting til the birds vacate the island?

Enter the porg. To erase the puffins from the scenery, the porgs were digitally inserted to overwrite the Terran birds. Furry, beakless avians, the porgs with their soft, round bodies, enormous eyes, and screepy vocalizations are almost definitively cute. As such, they were polarizing in the fandom - folks either adore them or despise them - which, perhaps paradoxically, is one of the defining characteristics of cuteness. As Sianne Ngai posits in her pathbreaking 2005 essay "The Cuteness of the Avant-Garde" - cuteness inspires both feelings of nurture and aggression. "The formal properties associated with cuteness - smallness, compactness, softness, simplicity, and pliancy-call forth specific affects: helplessness, pitifulness, and even despondency" (814).

Ngai emphasizes that one trait that is crucial to cuteness is "that its diminutive object has some sort of imposed-upon aspect or mien - that is, that it bears the look of an object not only formed but all too easily deformed under the pressure of the subject's feeling or attitude towards 
it." The porgs appear to be nothing if not put-upon (Figure 2) and, while largely hapless and helpless in their lived environment, they exert a agency by reflecting the pressure of feeling back at those who would exploit them. Much of the language that surrounds cuteness reflects the potential for cuteness inspiring, not cuddly feelings, but aggression - "I'll eat you up." "I'll squish you to bits." This language emphasizes the otherness of the cute as cuteness appears to invite the exercise of disproportionate power. This affect of malleability and helplessness compromises how the porgs exert agency in their lived environment and in their interactions with other beings. I see the porgs trying to exercise animal agency in two interesting ways. We witness the first when Chewbacca's dinner is interrupted by potent gaze of the porgs. The second is the porgs' occupation of the Millenium Falcon.

While waiting for Rey to conclude her business with Luke on Ach-To, Chewie settles down for a meal of spit-roasted porg. Eating frequently has a moral valence in the Star Wars universe: recall Jabba's gluttony - devouring living non-human animals with visible, visceral glee; or Luke's belligerent consumption of the green milk of the thala-siren. As he's about to bite into his meal, Chewbacca is confronted with the implacable, pleading gaze of his dinner's compatriots. He averts his eyes before frightening his interlocutors away with a roar. The porgs, using the only tools they have, attempt, apparently unsuccessfully, to change Chewie's affect. Wookies are omnivores those canines aren't just for show. And while Chewbacca's pleasure in his meal is disturbed, it is not thwarted.

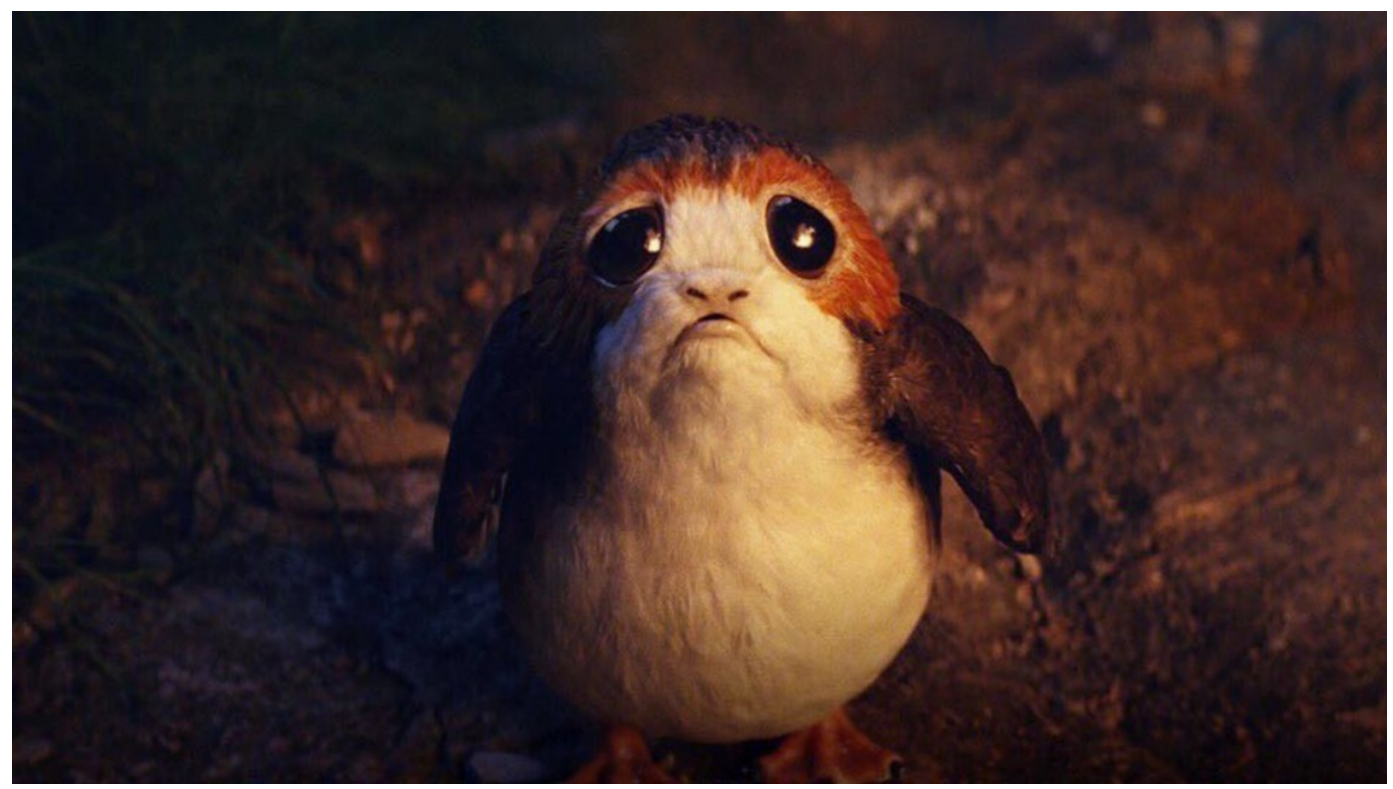

Figure 2: The implacable gaze of the porg The Last Jedi promotional image.

Thus I do not see porg agency acting in opposition to the instrumentalist dominance that typifies zooësis in the Star Wars universe, rather, to paraphrase philosopher Yi Fu Tuan, it is its anodyne (Tuan, 1-2). In Tuan's formulation, dominance mechanizes the relationships between humans and animals and reduces animals to their use value. The cuteness of the porg is palliative, and ultimately signals their helplessness and dependency; that the best mechanistic use of these otherwise hapless creatures is as nourishment for an alpha omnivore only serves to underscore the uselessness of cuteness as an antidote to violence. There is no more radical othering than to 
be rendered as meat. Chewbacca's apparent shame notwithstanding, we do not see him discard his meal. Rather he turns away from the gaze of the porg, avoiding the intended affect of pity or remorse. Cuteness is no defense against radical othering in the absence of other forms of agency. And the porgs' infestation of the Millennium Falcon is likewise not an effective act of resistance. Rather it becomes akin to a diaspora population - totally dependent on those who control their lived environment and ultimately, as we see with the porg's reaction to Chewie's piloting during battle, complicit in the violence of the dominant species.

With so many other ethical concerns in terms of representation of race and gender in the Star Wars universe, the problems with animal representation may seem like small potatoes. I see the treatment of animal others in the zooësis of Star Wars as part and parcel with these other problems of representation. How we treat animals is frequently how we treat other Others, and considering the animal is often a first step toward other reforms. So, as Ezra learns on Lothal, in considering the animal, we must consider their role and agency in their own right, not merely as extensions of human needs or affect, and interpret the use of animals not merely as metaphors for other forms of oppression.

\section{Bibliography}

Chaudhuri, Una, and Shonni Enelow. "Animalizing Performance, Becoming-Theatre: Inside Zooësis with the Animal Project at NYU.” Theatre Topics. Volume 16, Number 1, March 2006, pp. 1-17.

Ngai, Sianne. "The Cuteness of the Avant-Garde." Critical Inquiry. Vol. 31, No. 4 (Summer 2005), pp. 811-847.

Star Wars Rebels. "Spark of Rebellion." Season 1, episodes 1 \& 2. Directed by Steward Lee and Steven G. Lee. Written by Simon Kinberg. Aired September 26, 2014 on Disney XD.

Star Wars Rebels. "Empire Day." Season 1, episode 8. Directed by Steven G. Lee. Written by Henry Gilroy. Aired November 10, 2014 on Disney XD.

Star Wars Rebels. "Gathering Forces." Season 1, episode 9. Directed by Steward Lee. Written by Greg Weisman. Aired November 17, 2014 on Disney XD.

Star Wars Rebels. “A Fool's Hope.” Season 4, episode 14. Directed by Dave Filoni and Saul Ruiz. Written by Henry Gilroy and Steven Melching. Aired March 5, 2018 on Disney XD.

Star Wars Rebels. "Family Reunion - and Farewell." Season 4, episodes 15 \& 16. Directed by Dave

Filoni, Bosco Ng, and Sergio Paz. Written by Dave Filoni, Henry Gilroy, Kiri Hart, Simon Kanberg, and Steven Melching. Aired March 5, 2018 on Disney XD.

Star Wars: The Last Jedi. Directed by Rian Johnson. Lucasfilm, December 15, 2017.

Tuan, Yi Fu. Dominance and Affection: The Making of Pets. New Haven \& London: Yale University Press, 1984. 